\title{
PerCursos
}

\section{Mudanças climáticas e planejamento urbano: cenários futuros de aumento do nível do oceano no município de Itapema/SC}

\begin{abstract}
Resumo
O município de Itapema (SC) apresenta na sua história a atividade do turismo como um dos grandes fatores influentes no processo de urbanização. Praticamente quase toda a faixa da orla marítima encontra-se ocupada por edificações, salvo raras exceções que ainda preservam a mata nativa. A necessidade de preservar a orla constitui uma providência urgente diante das evidências do desequilíbrio climático. Os estudos apontam o aumento da temperatura global, degelos dos glaciais e aquecimento da água do mar, e consequente aumento do nível dos oceanos que irão impactar as zonas costeiras. Neste contexto de mudanças climáticas, o objetivo geral deste artigo foi identificar os possíveis impactos na área urbana de Itapema, decorrentes de cenários futuros do aumento do nível do oceano. O procedimento metodológico adotado foi de caráter exploratório, descritivo e propositivo relacionado ao objeto da pesquisa e quantiqualitativo no seu processo. Os resultados obtidos permitem prever os cenários futuros do aumento do nível do oceano através da cartografia elaborada com base no $5^{\circ}$ Relatório do Painel Intergovernamental de Mudanças Climáticas (AR5-IPCC 2014), por meio de diagnóstico e análise dos cinco recortes respectivos do município. Constatou-se a necessidade de se criar uma zona de proteção, e outra de amortecimento para prevenir e minimizar os futuros impactos. As áreas de mangues, restingas e algumas áreas edificadas são relacionadas como as mais vulneráveis ao aumento de nível do oceano. Espera-se que os resultados dessa pesquisa contribuam no planejamento de soluções para enfrentamento do impacto das mudanças climáticas de Itapema.
\end{abstract}

Palavras-chave: Mudanças climáticas. Planejamento urbano. Planejamento regional. Itapema (SC).

\author{
Samantha Jandrey \\ Mestre em Desenvolvimento \\ Regional pela Universidade \\ Regional de Blumenau - FURB. \\ Arquiteta e Urbanista pela \\ Universidade Regional de \\ Blumenau - FURB. \\ Brasil \\ arqsamanthaj@gmail.com
}

\section{Juarês José Aumond \\ Doutor em Engenharia Civil pela \\ Universidade Federal de Santa \\ Catarina - UFSC. Professor da \\ Universidade Regional de \\ Blumenau - FURB. \\ Brasil \\ juares.aumond@gmail.com}

\footnotetext{
Para citar este artigo:

JANDREY, Samantha; AUMOND, Juarês José. Mudanças climáticas e planejamento urbano: cenários futuros de aumento do nível do oceano no município de Itapema/SC. PerCursos, Florianópolis, v. 21, n.46, p. 25 - 53, maio/ago. 2020.
}

DOI: $10.5965 / 1984724621462020025$

http://dx.doi.org/10.5965/1984724621462020025 


\title{
Climate changes and urban planning: future scenarios for ocean level rise in Itapema, S.C.
}

\begin{abstract}
The municipality of Itapema (SC) has, in its history, the tourism activity as one of the major influencing factors in the urbanization process. Virtually almost the entire portion of the coastline is occupied by buildings, with rare exceptions that still preserve the native forest. The need to preserve the coastline is an urgent measure in the face of evidence of climatic imbalance. Studies point to an increase in global temperature, melting of glaciers and warming of seawater, and a consequent increase in the oceans' level that will impact coastal areas. In this context of climate change, this article's general objective was to identify the possible impacts on the urban area of Itapema, resulting from future scenarios of rising sea levels. The methodological procedure adopted was exploratory, descriptive, and propositional in nature, related to the research object and quantitative and qualitative in its process. The results obtained allow us to predict the future scenarios of the increase in the level of the ocean through the cartography elaborated based on the 5th Report of the Intergovernmental Panel on Climate Change (AR5-IPCC 2014), through diagnosis and analysis of the five respective sections of the municipality. There was a need to create a protection zone and a buffer zone to prevent and minimize future impacts. The areas of mangroves, sandbanks, and some built-up areas are listed as the most vulnerable to rising sea levels. It is expected that the results of this research will contribute to planning and solutions to face the impact of climate change in Itapema.
\end{abstract}

Keywords: Climate changes. Urban planning. Regional planning. Itapema (SC). 


\section{Introdução}

A cidade pode ser considerada um fato histórico, geográfico e, acima de tudo, social (FERRARI, 1984). As transformações estruturais da sociedade contribuíram para o crescimento das cidades contemporâneas e, consequentemente, a nossa sociedade está cada vez mais urbana. Logo, a cidade é um organismo vivo e complexo, continuamente em transformação, funcionando simultaneamente como palco, objeto e sujeito da sociedade que abriga. As forças produtivas sociais, em cada estágio de seu desenvolvimento, apresentam uma resultante espacial que é fruto do trabalho acumulado até aquele momento histórico. Cada geração deixa sua contribuição no espaço urbano, criando novas formas e estruturas, destruindo aqueles espaços que perdem suas funções e adaptando outros espaços a novas funções urbanas. Por esses motivos, a compreensão do espaço urbano pressupõe a compreensão de seu processo de formação ao longo do tempo (SIEBERT, 2000).

O fenômeno da urbanização é relativamente recente e crescente; com a expressiva contribuição do êxodo rural, o Brasil deu o maior salto populacional urbano de 1940 a 1980 (SANTOS, 1989). A esperança de melhores condições de vida levou a um aumento exponencial e não planejado das cidades (SPOSITO, 2005). Foi sinônimo da industrialização e da modernização, mas também da degradação ambiental e exclusão social.

Nesse contexto, para Maricato (2003) a urbanização trouxe expressivas mudanças à paisagem. Hoje, as cidades são o lugar da violência, das enchentes, da poluição, das favelas e dos desmoronamentos. A ocupação acelerada nas zonas costeiras acentua a vulnerabilidade do meio natural e urbano diante das mudanças climáticas. Segundo Maricato (2011) o maior crescimento das cidades de porte médio e das cidades litorâneas ocorre na década de 1980, com consequências socioambientais decorrentes do processo de urbanização.

Para Siebert (2013) as áreas urbanas são, ao mesmo tempo, responsáveis pelo aquecimento global e vítimas de suas trágicas consequências, em função do nosso modo de produção e consumo. Os fenômenos climáticos extremos têm atingido, com maior 
intensidade e frequência, as cidades ao redor do planeta, causando desastres socioambientais de grande magnitude. Uma das consequências desse desequilíbrio climático e do aquecimento é a elevação do nível do oceano.

Fica evidente, para Moura (2005), que as cidades estão mais vulneráveis aos impactos dos eventos climáticos. As pesquisas científicas apontam como efeito mais grave o aumento da temperatura global e suas consequências em função da industrialização e do processo urbano. Partes das cidades litorâneas carecem de preparo diante dos impactos de elevação do nível do oceano e do consequente avanço da lâmina de água sobre o continente e dos processos erosivos da costa (BRAUN, 2017).

O Quinto relatório IPCC (2014) apresenta um cenário pessimista e impactante em relação ao nível do mar médio global, com uma projeção de aproximadamente 0,98 m, até o final deste século. Esse fato torna evidente a importância da atuação das organizações públicas, especialistas acerca do planejamento urbano, nas buscas de alternativas para o enfrentamento dessa crise que envolve tanto os aspectos ambientais, como sociais.

Itapema localiza-se no litoral Norte de Santa Catarina (Brasil) e sua história evidencia um forte crescimento urbano, devido ao acelerado crescimento demográfico e da valorização turística, principalmente a partir da década de 80. Os aspectos econômicos, históricos, sociais, os condicionantes físicos e o aumento da atividade turística norteiam a construção do município, que é um dos principais balneários catarinenses. A localização geográfica e a densificação urbana das áreas litorâneas representam fatores determinantes de valorização. Em contrapartida, a gestão urbana não acompanha essa crescente demográfica, pois o último Plano Diretor do Município é do ano 2002, sendo que o mesmo deve ser revisado, no máximo, em 10 anos. E, não representa a atual dinâmica da cidade, em função disso, optou-se por não trabalhar com o Plano Diretor nesta pesquisa.

Fica evidente que o município, de um lado, vive uma cidade deslumbrante com suas edificações cada vez mais luxuosas e desenvolvidas e que atraem o capital e o turismo, e por outro, a Itapema carente, periférica, que o poder público e muitos turistas 
e cidadãos não querem ver. Essas disparidades ocasionam, muitas vezes, uma exclusão social dos indivíduos e acaba por afastá-los do seu pleno desenvolvimento na sociedade (GIDDENS, 2004).

Para Pinho e Reis (2013), destacam-se o crescimento urbano e o rápido aumento populacional que se desenvolvem à margem de um efetivo processo de planejamento que integre ações individuais em um projeto coletivo de cidade; vêm acumulando inúmeros problemas urbanos e socioambientais. Na urbanização, não se vêm respeitando critérios básicos de preservação ambiental, com invasões de áreas protegidas pela legislação federal, estadual e municipal.

Nesse contexto cabe questionarmos: como, em cenários futuros, Itapema poderá ser impactada pelo aumento do nível do oceano decorrente das mudanças climáticas? 0 objetivo deste artigo foi identificar as áreas suscetíveis à elevação do nível do oceano, em função das mudanças climáticas. Para tanto, foi realizado um mapeamento das áreas impactadas pela elevação do oceano. Em função da relevância deste município para o desenvolvimento econômico local e regional, este trabalho possibilitou uma compreensão dos impactos considerando os cenários futuros da transgressão marinha no município de Itapema. Além disto, a pesquisa contribui na identificação de áreas de risco socioambiental, e para a geração de ferramentas para o planejamento urbano.

\section{Área de estudo e suas características}

A faixa litorânea do Estado de Santa Catarina possui uma diversidade de paisagens naturais, apresentando-se como uma das mais belas orlas no Brasil. A beleza e a fartura de recursos naturais no litoral vêm sendo alvo de uma ocupação caótica e de exploração desorganizada e sem planejamento. Nesse movimento de transformação da paisagem, Reis (2009) esclarece que os núcleos pré-existentes foram adensados e expandidos, comunidades pesqueiras viraram balneários e novos assentamentos foram criados.

O litoral catarinense concentra a maior densidade populacional do estado, onde estão situadas algumas de suas principais cidades. Esse processo se dá de forma contínua e irracional para atender os migrantes e imigrantes, principalmente na porção norte do 
litoral, que dispõe de uma infraestrutura mais consolidada quando comparada com a porção do litoral sul, o que a torna mais dinâmica economicamente.

O município de Itapema localiza-se na Mesorregião do Vale do Itajaí, no estado de Santa Catarina, e destaca-se no cenário litorâneo. Possui cerca de 59.147 habitantes e área de 59,022 km². O município faz divisa com Balneário Camboriú, Camboriú, Porto Belo e Tijucas, além de ter seu território urbano cortado de norte a sul pela rodovia BR-101. Itapema apresenta aproximadamente $14 \mathrm{~km}$ de orla, composta por quatro praias: a praia da Mata de Camboriú, a praia da Ilhota, a praia do Cabeço ou Grossa e a praia de Itapema, a qual é dividida em Canto da Praia, praia central de Itapema e Meia Praia (IBGE, 2017).

Farias (1999) registra que Itapema apresenta uma memória urbana recente, portanto desprovida de construções associadas às origens da povoação, pois eram espalhadas ao longo das margens dos rios e da faixa de praia. Até 1960, a preferência era pela ocupação de áreas mais interioranas, principalmente no bairro Canto da Praia, o qual abrigava os pescadores e as famílias mais antigas do município. Itapema, bem como as cidades litorâneas, tem na atividade do turismo sua principal fonte de recursos.

O início acelerado do crescimento do balneário caracteriza-se a partir de 1970, continua na década seguinte com o aumento das construções, e atualmente se dá predominante e especialmente no bairro Meia Praia, caracterizado pelos edifícios de alto padrão.

Esse crescimento ocorreu sem obedecer a um plano diretor urbano de ocupação. As ruas e os bairros, frutos de loteamentos promovidos para atender à demanda do aumento populacional e, principalmente, de segunda residência para uso temporário, dirigiram e direcionaram o crescimento urbano de Itapema, com carência em infraestrutura de saneamento básico e abastecimento de água. Dezenas de novas construções estão surgindo a cada ano, criando uma barreira de concreto junto ao mar. Hoje paga-se um preço extremamente alto em investimentos de infraestrutura, controle de bens construídos e no uso do solo urbano (PINHO; REIS, 2013).

A implementação de equipamentos urbanos para tornar a cidade mais atrativa turisticamente acelerou o processo de ampliação da área urbana. É o caso do Projeto 
Orla, que estimulou a implementação do Parque Linear Calçadão de Meia Praia, propiciando-se mais atratividade para os turistas e para a população. A região proporciona uma ótima opção de lazer à beira-mar, visto que o calçadão possui academias de ginástica ao ar livre para população. Além do valor de uso, o calçadão acaba colaborando para conter a ocupação irregular na orla.

Por outro lado, a população menos abastada tende a ocupar a região a oeste da rodovia BR-101. Sem condições de adquirir imóveis nas áreas valorizadas, acomoda-se em bairros mais afastados e forma bolsões de pobreza nas regiões periféricas. Segundo Damiani (2006), mesmo o município possuindo um índice alto de desenvolvimento humano não significa que o desenvolvimento dos seus habitantes seja igualitário. Dessa forma, à medida que uma região se urbaniza, o contraste entre as localidades centrais e periféricas da cidade torna-se mais acentuado e evidente.

Atualmente, podem ser observados os impactos causados pelas construções em áreas de risco como mangues, restingas e ocupações irregulares próximas ao mar. De outra forma, com o estímulo da especulação imobiliária e autorização da administração municipal, os prédios cada vez mais elevados alteram as condições ambientais da praia e induzem a erosão devido à supressão da vegetação de restinga. Essa degradação não só acarreta perda de biodiversidade, pela diminuição de locais passíveis da reprodução da vida, como também apresenta problemas para o homem, como perdas culturais e econômicas, esta última a mais sentida (SILVA, 2013).

Nesse contexto, o município de Itapema vivenciou uma expansão do espaço urbano sem planejamento, com excessivas edificações e densificação urbana, loteamentos em áreas de proteção permanente e terras da União, sem que tenha havido atuação ostensiva dos órgãos de fiscalização patrimonial e ambiental. Diante da perspectiva de mudanças climáticas, da elevação do nível do oceano e de eventos meteorológicos extremos, a fragilidade do espaço urbano é intensificada e diminui a resiliência da cidade de Itapema. 


\section{Fundamentação teórica}

A mudança climática é a dimensão mais urgente, mais grave e mais profunda da crise ambiental do século XXI. É urgente porque resta pouco tempo para estabilizar a concentração de gases de efeito estufa em níveis aceitáveis na atmosfera. É grave porque aumenta significativamente a desertificação, a crise de recursos hídricos e a crise de perda da biodiversidade. Além disso, destrói a infraestrutura existente, gerando grandes prejuízos às atividades econômicas e afetando com severidade as populações mais pobres do planeta. Ela é profunda porque não existe solução apenas tecnológica. Trata-se de buscar fontes renováveis de energia, mas isso significa, também, o fim de uma civilização baseada nos combustíveis fósseis e na depreciação acelerada de imensos volumes de capital imobilizados nela (GIDDENS; VIANNA, 2010).

Conforme descreve Moura (2005), a Terra sempre esteve submetida a constantes alterações climáticas, em ciclos de milhares de anos de aquecimento e glaciação causados por fenômenos naturais. A partir da Revolução Industrial, o planeta passou a enfrentar uma nova realidade: a mudança de temperatura provocada pela poluição humana. Esse problema começou a ser sentido nos microclimas, com o aumento da temperatura nos grandes centros urbanos e, mais recentemente, no macroclima, com as mudanças climáticas globais, a potencialização do efeito estufa e seus desdobramentos mais relevantes para esta pesquisa: o degelo, a expansão térmica das águas dos mares e oceanos e o aumento de nível do mar e transgressão marinha nas zonas costeiras.

Siebert (2013) comenta que uma parcela significativa das causas antropogênicas das mudanças climáticas globais são as emissões dos gases de efeito estufa. De acordo com a autora, $80 \%$ das emissões de carbono responsáveis pelo efeito estufa são provenientes das áreas urbanas. O fenômeno do aquecimento global é causado pelo acúmulo excessivo de gases de efeito estufa, como o monóxido de carbono (CO), o dióxido de carbono $\left(\mathrm{CO}_{2}\right)$ e o metano $\left(\mathrm{CH}_{4}\right)$, entre outros de menor incidência. Consideravelmente, aumenta a absorção da radiação de infravermelho, aumentando, também, a temperatura do ar e fazendo com que mais vapor de água seja formado (e retido). O resultado é um aumento de nuvens, que também absorvem o infravermelho e, 
por efeito semelhante a uma estufa, aumentam mais a temperatura média global, interferindo sobre o equilíbrio energético do planeta (LABOURIAU, 1998).

Nessa perspectiva, existem quatro responsáveis por essas mudanças: a expansão térmica do oceano, o derretimento dos glaciares de montanha, o derretimento das calotas de gelo dos extremos da Terra e o aumento do nível atual do oceano. Moura (2005) argumenta que o derretimento das calotas polares, que levará ao aumento do nível dos oceanos e a inundações, é um fenômeno que se retroalimenta, já que a reflexão do gelo diminui quando ele derrete e, sendo o oceano de cor escura, absorve mais calor e acelera o processo de derretimento. Trata-se de um processor de retroalimentação positiva. Além disso, o gelo que derrete libera uma quantidade significativa de carbono na atmosfera, contribuindo ainda mais para o efeito estufa.

Decorrente dessa concentração de gases e da ampliação do Efeito Estufa, estimase que ocorreu um aquecimento médio do planeta de $0,85^{\circ} \mathrm{C}$ ao longo do período entre 1880-2012. Além do mais, cada uma das três últimas décadas têm sido sucessivamente mais quente que a anterior, em comparação a qualquer período desde 1850. Tais alterações no clima global, e seus impactos sobre o meio ambiente, são ônus incidindo ao longo das gerações devido às questões ambientais não resolvidas desde a intensificação do modelo industrial e da urbanização. Além das transformações já ressaltadas, e das mudanças em curso, a emissão contínua de GEE causará ainda mais aquecimento e alterações em todos os componentes do sistema climático (IPCC, 2014).

As mudanças climáticas nas zonas costeiras podem causar um incremento nos riscos nas cidades, de três maneiras: a partir do mar, através do aumento do nível dos oceanos, devido ao incremento no derretimento de glaciares; das tempestades, pela chuva, devido a precipitações mais fortes ou mais prolongadas; e por mudanças que aumentam o fluxo dos rios, devido à impermeabilização do solo. Portanto, o aumento da temperatura leva a mudanças climáticas como o derretimento do gelo nos polos, alterações das correntes marítimas e o aumento do nível dos oceanos (UNITED NATIONS HUMAN SETTLEMENTS PROGRAMME, 2011). 
Durante o século XX, foram registradas mudanças eustáticas da ordem de 19 centímetros de aumento médio global do nível do oceano, e os modelos climáticos para o final do século XXI sugerem a possibilidade de aumento médio de 82 centímetros do nível global (UNITED NATIONS HUMAN SETTLEMENTS PROGRAMME, 2011). Mesmo nos cenários mais otimistas, quanto às ações de mitigação das mudanças climáticas, a eustasia continuaria a ocorrer, impactando cidades litorâneas devido à transgressão marinha.

As zonas costeiras do mundo abrigam cerca de dois terços da humanidade e concentram a maior parte das metrópoles contemporâneas (MORAES, 2007). Esse é um amplo espaço de interação setorial, institucional, demográfica e urbana, no qual as complexas relações entre o homem e o meio afetam a dinâmica ambiental. As cidades buscam como vetor de desenvolvimento econômico as estratégias de desenvolvimento atreladas ao turismo imobiliário. O crescimento urbano dos municípios costeiros ocorre devido à urbanização, turismo e à atividade de construção civil, que juntas, configuram-se como os elementos impulsionadores dessa transformação, que promovem a alteração do uso do solo e a expansão do seu território, concedendo a esses locais a polarização de empregos e investimentos. Além de reproduzir os processos de valorização do espaço comum.

Para Souza e Rodrigues (2004), o planejamento urbano, como qualquer tipo de planejamento, é uma atividade que remete sempre para o futuro. É uma forma que os homens têm de tentar prever a evolução de um fenômeno ou de um processo, e, a partir desse conhecimento, procurar se precaver contra problemas e dificuldades, ou ainda aproveitar melhor seus possíveis benefícios.

Conforme explicam Pollete e Lins de Barros (2012), a necessidade de integração das políticas ambientais com os avanços obtidos na política urbana nas últimas décadas pode ser considerada um dos grandes avanços na gestão territorial do Brasil. A respeito de mudanças climáticas e elevação do nível do mar, algumas capitais litorâneas no Brasil já incorporaram, em seus planos diretores, diretrizes e estratégias, a exemplo dos municípios de Florianópolis (SC), Rio de Janeiro (RJ), Salvador (BA), Recife (PE), Santos (SP). 
As cidades devem estar, portanto, no centro das discussões sobre mudanças climáticas, seja qual for a perspectiva, de mitigação ou de adaptação. Na perspectiva da mitigação das mudanças climáticas, ou seja, da redução da emissão de GEE, o planejamento urbano cumpre um papel fundamental, na medida em que a forma como se estruturam as cidades e como se dão os usos do solo afeta a demanda urbana por energia (BRAGA, 2012). Assim, a influência humana no sistema climático é inquestionável, em razão de constantes emissões antropogênicas de gases causadores do efeito estufa, sendo esse um dos maiores paradigmas científicos da atualidade.

\section{Materiais e métodos}

A metodologia trata do caminho do pensamento e da prática exercida na abordagem da realidade (MINAYO et al., 1994). Esta pesquisa foi baseada na análise de cenários futuros de um fenômeno natural, sob a influência antropogênica, e das consequências diretas deste sobre o espaço urbano. Partindo de uma situação atual do contexto urbano ambiental do município de Itapema, pretendeu-se diagnosticar e analisar os impactos futuros em decorrência das mudanças climáticas, perante os cenários de elevação do nível do oceano no período de 2030 a 2100, no município de Itapema.

Para o desenvolvimento das projeções de cenários foram utilizados softwares de geoprocessamento. Essa metodologia é uma adaptação da metodologia de Moura (2005), que realizou análises de simulação por modelagem de cenários-tendenciais, para identificar áreas vulneráveis a inundação pelo aumento do nível do oceano. O resultado deste trabalho é uma ferramenta para futuro planejamento de uso e ocupação do solo nas zonas costeiras de Itapema que contemplem as alterações físicas provocadas pela elevação do nível do oceano devido às mudanças climáticas. Cabe salientar que esta pesquisa não tem a pretensão de detalhar os vários impactos da elevação do nível do oceano sobre o espaço urbano e sim caracterizar a área invadida por ele.

Os dados de cenários utilizados foram referentes às previsões do IPCC, publicados no $5^{\circ}$ Relatório, do ano de 2014. Com uma perspectiva de aumento do nível do oceano 
para 2030 de: 0,10m (cenário otimista) e 0,15m (cenário pessimista). E para o ano de 2100, o panorama é de um aumento de 0,60m (cenário otimista) e de 0,98 m (cenário pessimista) ${ }^{1}$. Dessa maneira, foram analisadas as mudanças dos cenários projetados para os recortes nas unidades delimitadas na área de estudo. As imagens aéreas utilizadas permitiram analisar a densidade de áreas ocupadas, advindas da base de dados matriciais (Modelo Digital de Terreno - MDT) da Secretaria de Estado de Desenvolvimento Econômico e Sustentável, para posteriormente adequá-las para representarem da melhor forma os aspectos da área estudada.

Para a aplicação da modelagem com os mapas foi utilizada como base imagem aérea (Google Satellite). O processamento consiste na extração de dados vetoriais para composição da topografia das áreas analisadas. Esse processo foi feito com equidistância entre contornos de $0,1 \mathrm{~m}$, de forma a obter curvas de nível a cada $10 \mathrm{~cm}$. Os processamentos e geração dos mapas foram realizados nos softwares QGis e ArcGIS. Foram realizados os mapeamentos das áreas consideradas mais vulneráveis com projeções para cenários de 2030 e 2100 . Nesse sentido, criaram-se quatro classificações de manchas de elevação do oceano para cada área de estudo: a) de 10 a 20cm; b) de 10 a $50 \mathrm{~cm}$; c) de 10 a $100 \mathrm{~cm}$;) de 10 a $200 \mathrm{~cm}$. Essa demarcação é feita por manchas com "escala de valores" de cor, mostrando diferentes influências do oceano sobre o município, e não incluem as variações das marés e os efeitos das contribuições pluviométricas.

Portanto, as áreas da zona costeira que serão atingidas com o aumento do nível do oceano no município de Itapema são consideradas estratégicas e circundam etapas de análises, interpoladas pelo cruzamento das informações das leituras de campo, dado pelo cenário atual. E pelas cartografias de projeções dos cenários em dois períodos temporais estipulados em 2030 e 2100. Cabe ressaltar que a pesquisa limitou-se a identificar áreas

\footnotetext{
${ }^{1}$ Baseados no $5^{\circ}$ relatório do IPCC (2014), para o nível do oceano médio global: RCP2.6 (cenário otimista) é o cenário de menor dano, cuja premissa parte do comprometimento da humanidade para evitar o aquecimento que seria máximo. Nesse caso, o aumento médio da temperatura global oscilará entre $0,30 \mathrm{C}$ a 1,70C; RCP8.5 (cenário pessimista) é considerado o cenário pessimista, caso não sejam tomadas as providências necessárias para lidar com as mudanças climáticas. Nesse caso, o aumento médio da temperatura global oscilará entre $2,60 \mathrm{C}$ a $4,80 \mathrm{C}$.
} 
suscetíveis à invasão do oceano e, a partir disso, a necessidade de restringir o uso do solo e recomendar novos usos, como áreas de lazer e de preservação ambiental.

A zona costeira de Itapema constitui as cinco áreas de recorte distintas a serem analisadas neste trabalho. A pesquisa busca esclarecer o processo de transformação urbana e ambiental na zona costeira de Itapema, de modo a registrar e fazer os apontamentos das modificações ocorridas, através da caracterização de cada área de recorte, definidas como: Área de Recorte de Ilhota, Área de Recorte do Canto da Praia, Área de Recorte do Centro, Área de Recorte de Meia Praia e Área de Recorte do Rio Perequê (Figura 01).

Figura 01 - Áreas de recortes destacadas para caracterização

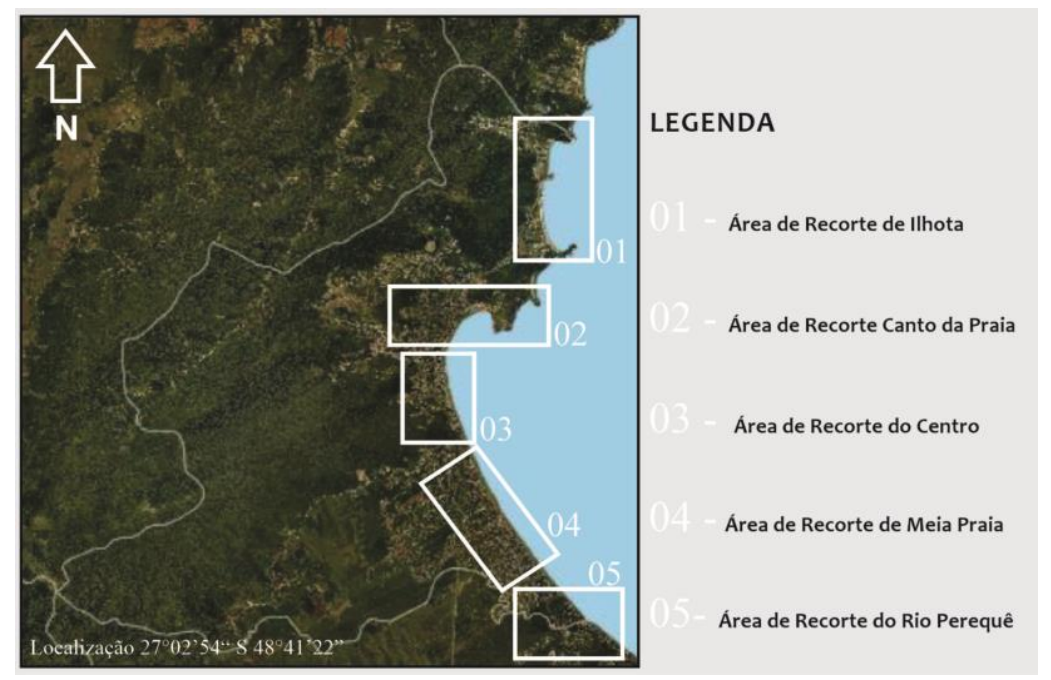

Fonte: Adaptado de Santa Catarina - SIGSC (2012).

A última etapa consistiu no cruzamento de dados levantados nas etapas anteriores para a elaboração do prognóstico que servirá de ferramenta para a geração de subsídios que auxiliarão no planejamento urbano. Nessa fase, buscou-se respostas para as questões norteadoras, relacionando-as e confrontando-as com os dados obtidos e a literatura abordada no marco teórico. Configurou-se, ainda, pela proposição de possíveis respostas e diretrizes direcionadas à elaboração de recomendações, inclusive no que se refere ao desenvolvimento de pesquisas futuras. 


\section{Resultados}

\section{Área de recorte de ilhota}

O Bairro Ilhota retrata um cenário de elementos paisagísticos importantes na zona costeira em estudo. O Bairro apresenta um costão aberto com áreas cobertas por matas de vegetação nativa preservadas contrastando com as pedras e o mar.

A urbanização da zona costeira pela vertente cultural e ambiental, de acordo com Strohaecker (2008), amplia o seu caráter singular, identificando-a como espaço de lazer, recreação e, em alguns casos, de preservação. Nesse sentido, o processo de urbanização se consolida espacialmente, com a implantação de loteamentos, condomínios verticais e horizontais para fins de segunda residência temporária nas proximidades dos grandes centros urbanos, e de complexos hoteleiros e resorts para o mercado turístico nacional e internacional em áreas privilegiadas pela beleza cênica. No município de Itapema, a tendência dos condomínios fechados também é visível, especialmente no Bairro llhota.

O Bairro Ilhota apresenta uma área turística consolidada a Leste da BR-101, na qual a Praia de Ilhota é um dos principais atrativos naturais; suas águas são cristalinas, e devido às ondas fortes, tornou-se a preferida dos praticantes de surfe. A região é bastante conhecida por ter uma grande concentração de restaurantes de alta gastronomia, especializados em frutos do mar. No ano de 2014, a Prefeitura de Itapema iniciou a obra de revitalização de 450 metros da orla.

A Figura 02 mostra as diferentes áreas ocupadas pela lâmina d'água na área de estudo referente ao recorte do Bairro Ilhota, nos diferentes cenários de elevação do nível do oceano. De acordo com a cartografia elaborada com projeção de 2030 e 2100, a área mais impactada é próxima à Foz do Rio da Mata de Camboriú. Nesse mesmo local, são frequentes os impactos das ressacas, a exemplo do transecto de outubro de 2017; nessa ocasião danificou boa parte da infraestrutura da orla. Conforme Gomes (2018), esses problemas não são oriundos da elevação no nível do oceano, porém estão intrinsecamente associados à fragilidade da costa do Setor Litoral Centro-Norte de Santa Catarina. 
Mudanças climáticas e planejamento urbano: cenários futuros de aumento do nível do oceano no município de Itapema/SC

Também é possível observar, na figura 02, a área atingida do lado oeste da BR-101, no bairro Ilhota, sujeita a alagamentos em função do curso d'água no local e da cota da planície, impactando na grande maioria das edificações residenciais.

Os cenários para 2100 apresentam uma transgressão marinha ainda mais conclusiva, sendo que ainda, devido a eventos ambientais como ressacas, marés e intensa dinâmica pluviométrica, já intensificaria os períodos de alagamento. Acredita-se que com a implantação da orla e mais recentemente a vegetação de restinga, os impactos sejam minimizados.

Figura 02- Projeção do cenário futuro na área de recorte de Ilhota

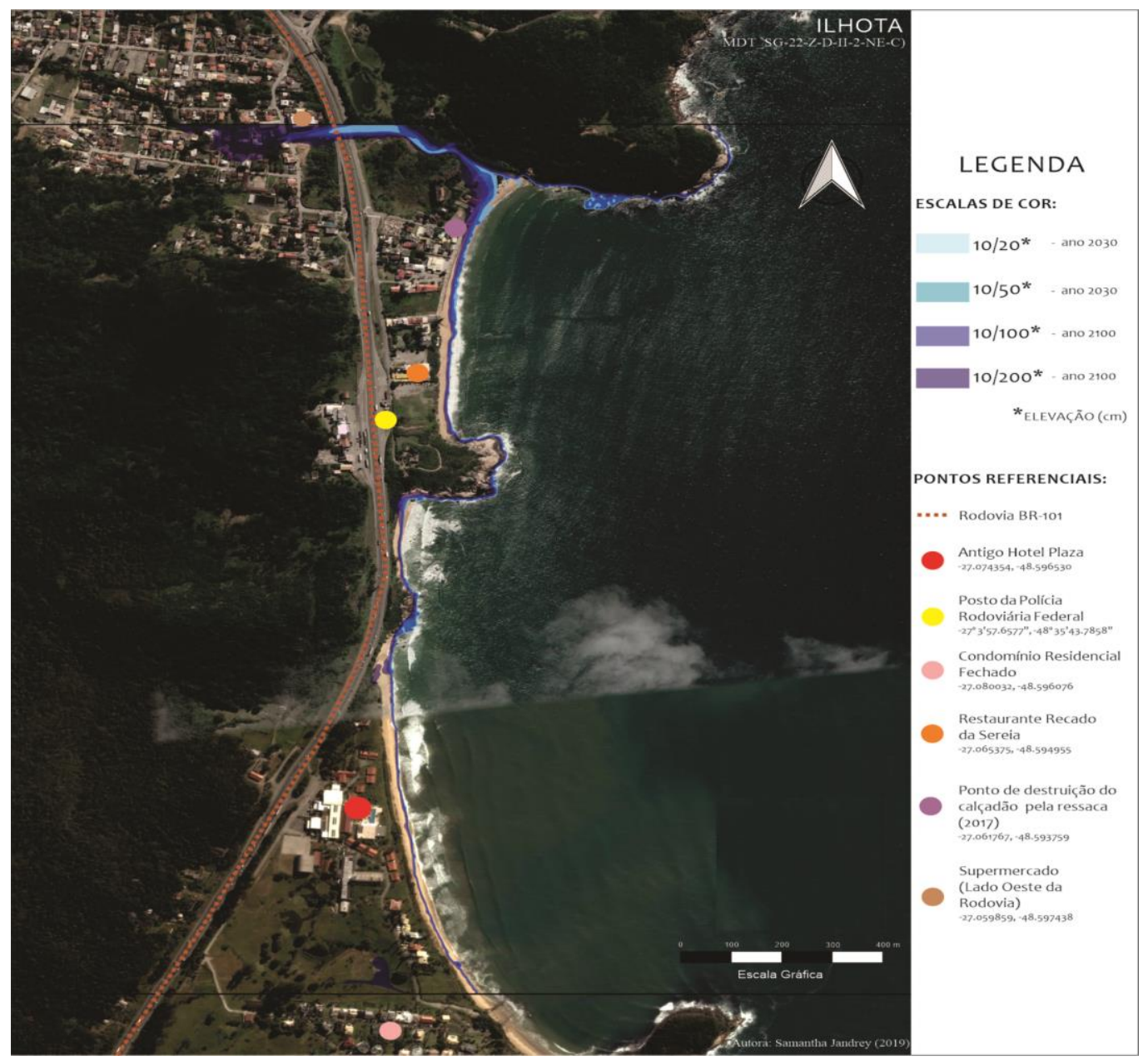

Fonte: Elaborado pela autora, 2019. 


\section{Área de Recorte do Canto da Praia}

Conhecida por abrigar os pescadores e as famílias mais antigas do município, é até reduto de pescadores, que moram no local ou em suas proximidades. Assim como em outras partes de Itapema, alguns prédios e casas de alto padrão estão presentes na orla dessa praia, contrastando com uma parte em que diversas casas simples de pescadores resistem à especulação imobiliária no lugar. O bairro dispõe de diversos estabelecimentos comerciais, principalmente peixarias e hotéis. Essa segregação produz o desenvolvimento e a apropriação desigual do território, como das riquezas sociais e dos seus recursos naturais, fazendo com que a cidade se constitua em território que potencializa e evidencia as desigualdades econômicas e sociais, que se expressam também nas disputas pelo espaço de moradia (SCHIMIGUEL, 2016).

Por meio das projeções aplicadas pelo Modelo Digital de Terreno fornecido pelo site do Sistema de Informações Geográficas da Secretaria de Estado do Desenvolvimento Econômico Sustentável de Santa Catarina, para o cenário de 2030 e 2100 (Figura 03), constatou-se: as áreas mais sujeitas à elevação do oceano são próximas aos cursos d’água, bacia do Rio Areal e Fabricio, devido ao seu perfil baixo. Essa situação é ainda mais preocupante. Verificou-se que uma área significativa estaria sujeita a cenários futuros da elevação do nível dos oceanos, exatamente em um local de densa ocupação urbana, principalmente residências. 
Figura 03- Projeção do cenário futuro na área de recorte de Canto da Praia

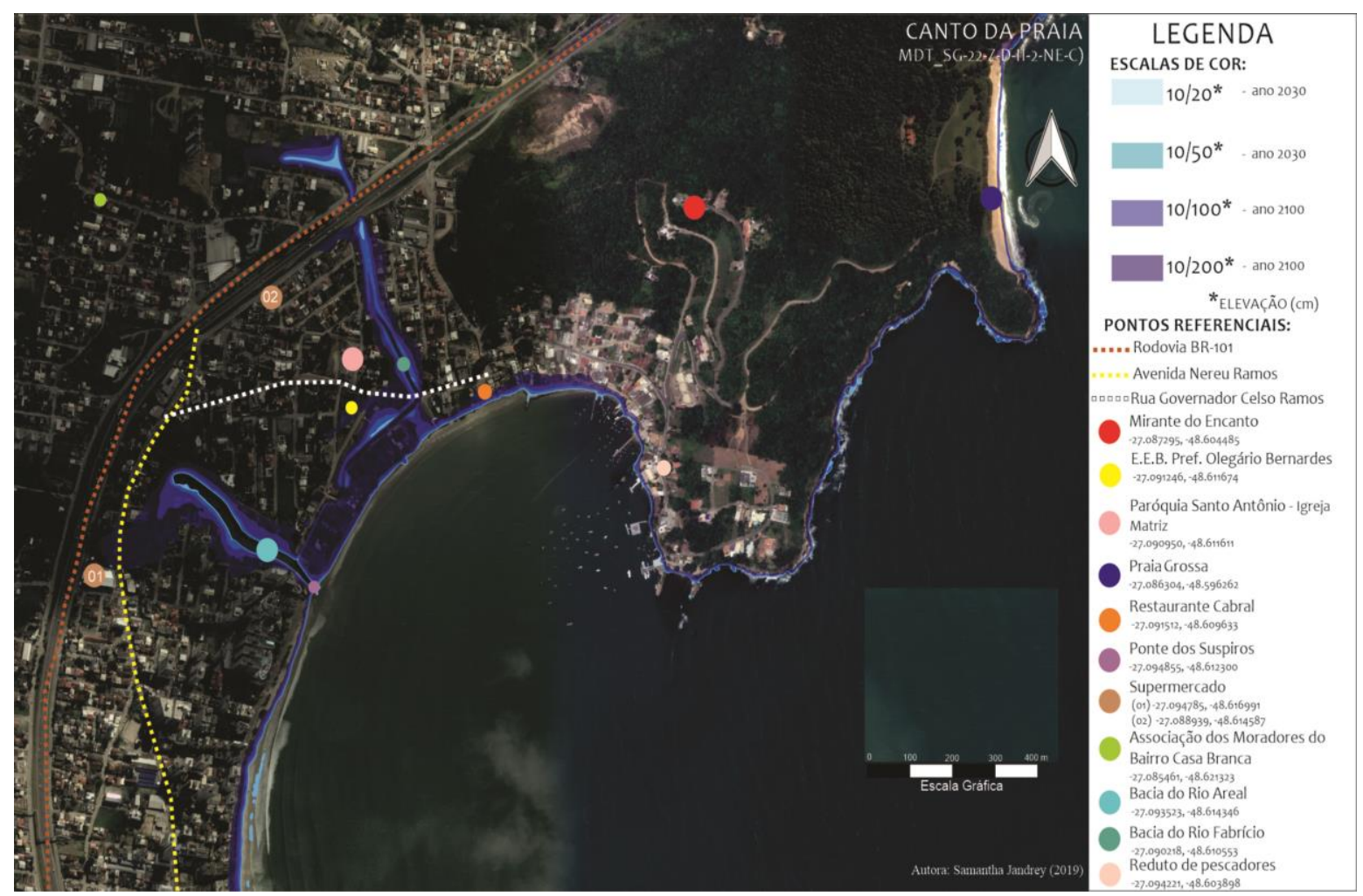

Fonte: Elaborado pela autora, 2019.

A inexistência da restinga e de suas micro dunas associadas impedem o amortecimento dos eventos das marés e ressacas. Incontestavelmente, isso irá produzir sérios prejuízos à economia local, sobretudo em relação ao comércio e às edificações que de forma crescente vêm surgindo no bairro, tendo em vista o processo de especulação imobiliária vivenciado nos últimos anos. Essa transgressão marinha atingiria as primeiras edificações em toda a extensão da orla nessa área, mesmo nos cenários de 2030 do IPCC. Observando a projeção para 2100, os cenários apresentam uma transgressão ainda mais expressiva e agravante.

\section{Área de Recorte do Centro}

De acordo com Schimiguel (2016), o povoado começou a se formar na área onde atualmente encontramos o centro de Itapema, estendendo-se ao extremo norte do Município, no qual hoje fica o bairro Canto da Praia. A verticalização, com as construções e edifícios de alto padrão, e a oferta de serviços nessa área têem crescido vertiginosamente, uma vez que esses bairros têm atraído a população de alta renda, e 
essas áreas vêm se evidenciando não só por seu adensamento, mas pela intensificação na oferta de serviços e infraestruturas que o acompanha.

Para Silva (2013), os equipamentos públicos, a proximidade dos serviços e dos centros administrativos e comerciais tornarão o espaço construído mais procurado e, consequentemente, mais valorizado. Essa dinâmica não ocorre de forma homogênea no espaço urbano, ela é seletiva, pois busca as melhores áreas, aquelas mais valorizadas. É nesse espaço em que ocorre mais efetivamente o processo de verticalização, pois a localização influencia na valorização do capital e, consequentemente, nos preços (SCHIMIGUEL, 2016).

$\mathrm{Na}$ Figura 04, têm-se os cenários futuros da elevação do nível dos oceanos resultantes da modelagem cartográfica do Bairro Centro. Mesmo nos cenários previstos de 2030, haverá a transgressão da faixa de areia, chegando à Rua Orla do Centro. Em alguns pontos, percebe-se a água atingindo as primeiras edificações da orla. Acredita-se que nos cenários mais amenos de eustasia essa área também será afetada. De acordo com Gomes (2018), apesar da cota de elevação da água atingir uma área menor, a natureza fluida das águas e a impermeabilidade do solo trazem a certeza de que as áreas de alagamento serão muito maiores. 
Figura 04- Projeção do cenário futuro na Área de Recorte do Centro

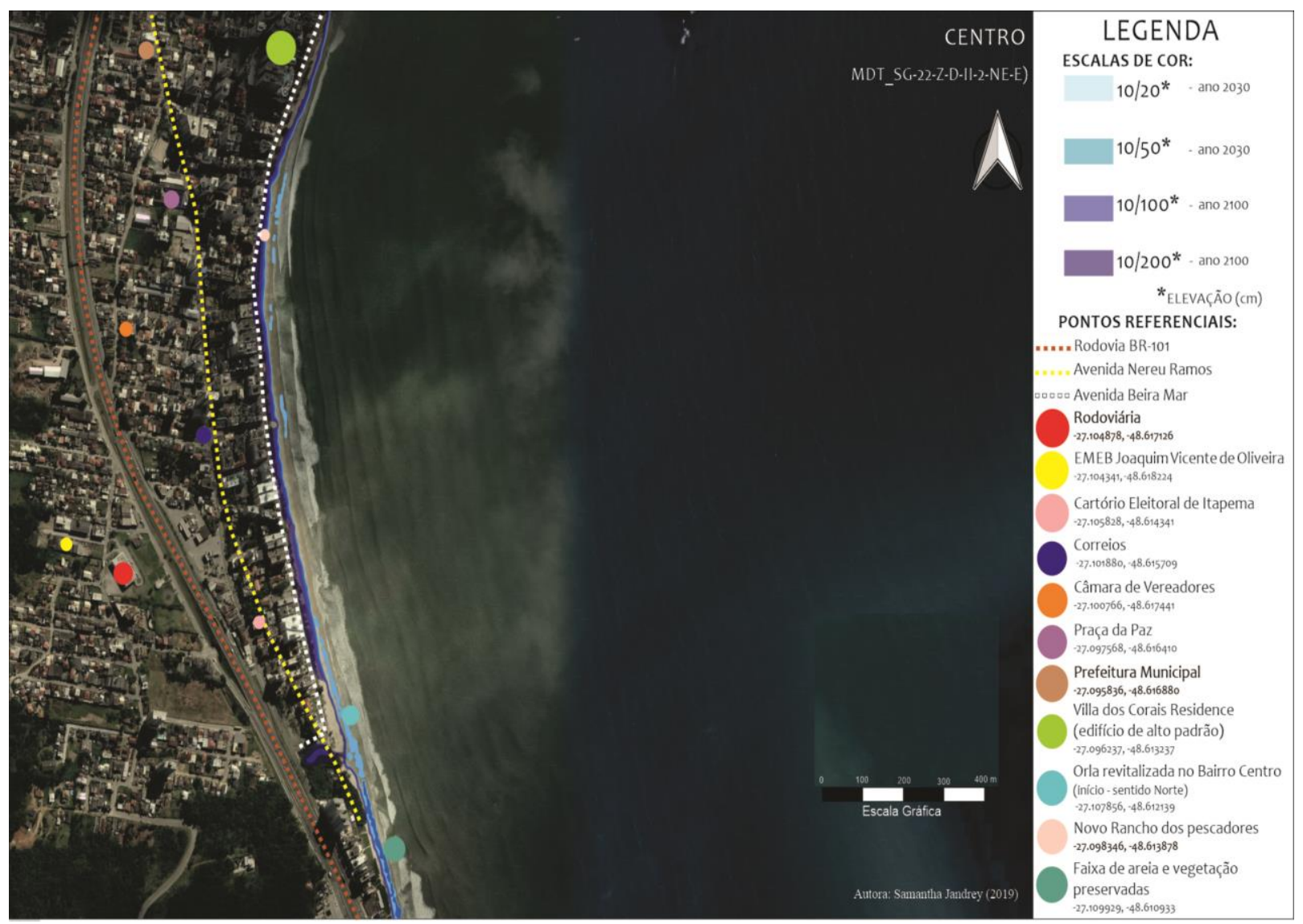

Fonte: Elaborado pela autora, 2019.

Na divisa entre os Bairros Centro e Meia Praia encontra-se uma vegetação mais preservada de restinga, num melhor estágio de conservação. Para Gomes (2018), com o processo de eustasia, as áreas afetadas seriam a do entorno do córrego, sendo que na orla, onde se tem um cordão de dunas e a proteção da restinga, a transgressão marinha não chegaria até as primeiras edificações. No entanto, com a sucessão ou o acúmulo de outros eventos ambientais e climáticos, mesmos nos estágios mais amenos de eustasia, seria suficiente para a transformação da paisagem local. Não obstante, algumas questões devem ser mais bem avaliadas, porque a transgressão marinha impactará o ecossistema de restinga modificando suas características naturais e a possível perda dos serviços ecossistêmicos atuais. 


\section{Área de Recorte de Meia Praia}

O bairro denominado de Meia Praia tem como limites, ao norte, o Bairro Centro; ao sul, o Rio Perequê; a leste, o Oceano Atlântico; a oeste, a Rodovia Federal BR 101. É o bairro que possui a melhor infraestrutura de serviços, representada pelos equipamentos e serviços como bares, restaurantes, hotéis, shoppings, comércio e outros, sendo também o bairro com a maior quantidade de edificações, resultando no adensamento populacional. Como resultado, nos últimos anos, Itapema passa por um acelerado processo de verticalização e especulação imobiliária, notadamente a orla. As transformações da paisagem foram inevitáveis; a evolução da construção vertical implicou no desaparecimento de moradias que serviam de residência aos pescadores locais, e principalmente das áreas verdes.

Para Farias (1999), a Meia Praia se tornou o ponto de maior interesse dos veranistas, motivados pela balneabilidade do mar e das águas calmas, quentes e pouco profundas, pois as demais praias existentes no município apresentam dificuldades de balneabilidade.

As transformações que o bairro Meia Praia apresentou na sua dinâmica econômica e social foram bastante amplas e dinâmicas na sua evolução. Em sua origem histórica, era formado por habitações de ocupação simples que evoluíram, sobretudo, com o processo de verticalização e adensamento imobiliário. Para Zemke (2007), essa transformação compreende não apenas a produção de bens materiais como também a adequação do meio ambiente físico circundante às necessidades individuais e coletivas.

Após a aplicação da ferramenta de geoprocessamento com as cotas de elevação do nível do mar consideradas pelo IPCC, a análise da imagem obtida (Figura 05), somada às observações realizadas em campo, confirmou que este é o bairro que mais tem sofrido transformações socioeconômicas no município devido ao crescimento do turismo e à especulação imobiliária. A Área de Recorte de Meia Praia é a região de maior densidade urbana e a que mais sofreu crescimento e transformação devido à intensa intervenção urbana, notadamente a partir da década de 70 do século passado. 
Mudanças climáticas e planejamento urbano: cenários futuros de aumento do nível do oceano no município de Itapema/SC

Samantha Jandrey, Juarês José Aumond

$\mathrm{Na}$ área mais ao Norte, onde a restinga está mais conservada e o número de empreendimentos imobiliários é menor, observa-se que o território é menos impactado. Mesmo na projeção de cenário para o ano de 2100, essa é a área que será menos impactada com a elevação do nível do mar. Presume-se que a preservação da vegetação de restinga e das microdunas deverá se constituir em uma competente barreira para o avanço do oceano. Entretanto, é importante considerar que, mesmo assim, as características naturais sofrerão grande impacto..

Figura 05- Projeção do cenário futuro na Área de Recorte Meia Praia

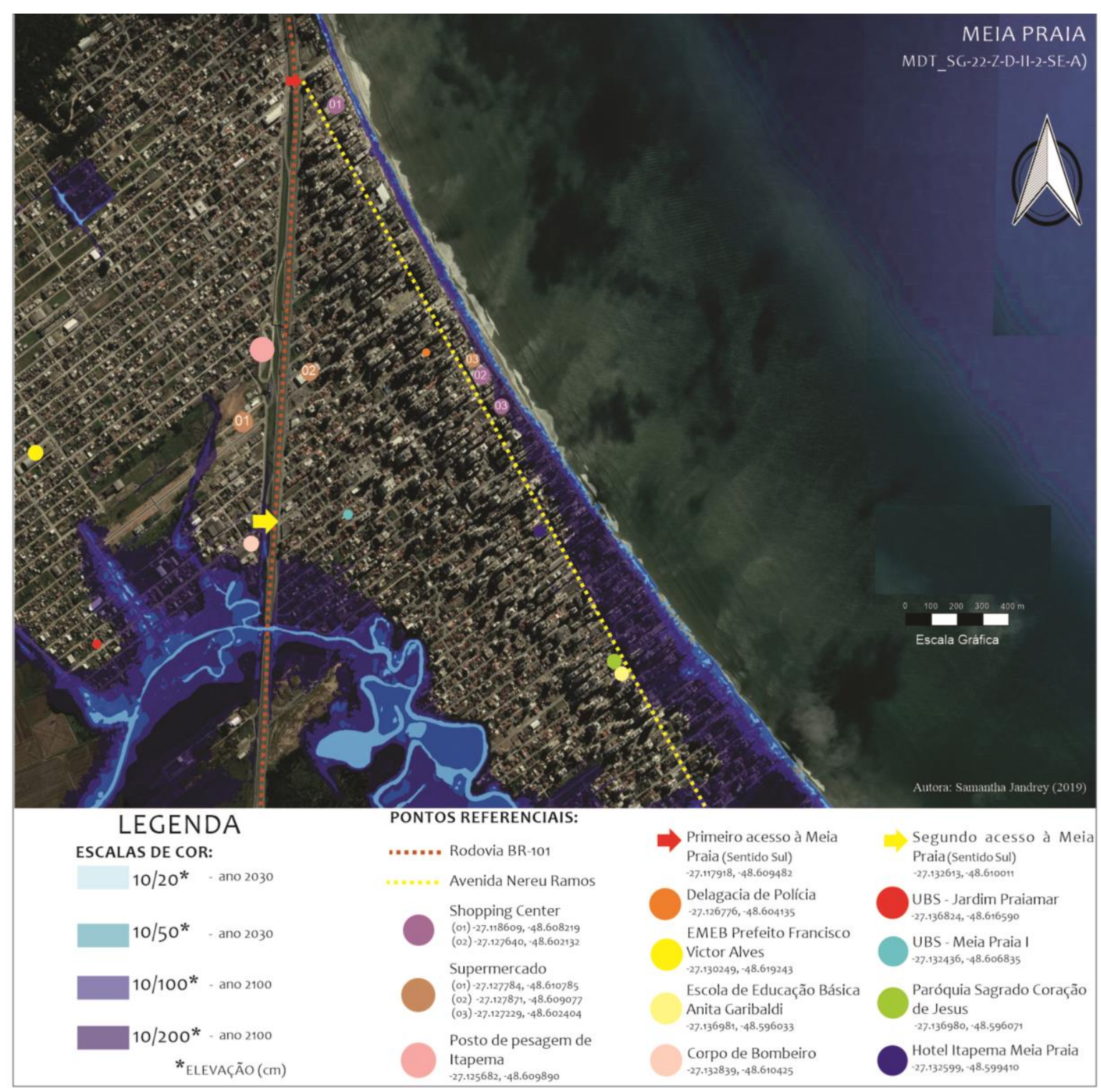

Fonte: Elaborado pela autora, 2019. 
A análise da imagem do Bairro de Meia Praia confirma a intensa urbanização ao longo de toda a sua orla e um estreitamento da faixa de areia onde houve a supressão da vegetação de restinga. Na projeção do cenário do aumento do nível do oceano para 2030, é perceptível a submersão da faixa de areia pela água do mar. Na projeção para 2100, a transgressão marinha é ainda mais impactante, pois excederia as limitações do Parque Linear Calçadão (PLC).

Nessa perspectiva, Gomes (2018) afirma que a orla é margeada pelo calçadão que substituiu a vegetação de restinga e, atualmente ocorrem algumas poucas espécies de plantas exóticas e gramíneas com função ornamental, mas que não prestam os serviços ecossistêmicos da restinga original. Existem, no entanto, nesta orla, uma série de comodidades voltadas ao veranista como quiosques, bancos de descanso, chuveiros e banheiros. Assim como em toda orla, o trânsito de automóveis se dá apenas na Avenida Nereu Ramos, do outro lado do quarteirão. Os prédios variam segundo o número de andares, mas permanece a tendência do processo de verticalização dos prédios.

Na data da vistoria de campo (transecto de junho de 2017), registrou-se que a maré avançou significativamente sobre a faixa de areia. Nos cenários tanto otimista quanto pessimista de elevação do oceano para o ano de 2100, as projeções indicam que a transgressão marinha chegará próximo da Avenida Nereu Ramos, área de grande impermeabilização do solo devido à elevada concentração de empreendimentos. Esse fato é relevante porque essa área é a que centraliza grande parte do comércio de Itapema e terá grande impacto socioeconômico.

\section{Área de Recorte do Perequê}

O Rio Perequê, que serve de limite para os municípios de Porto Belo e Itapema, caracteriza-se como principal curso d’água da região, utilizado para o abastecimento público dos municípios de Porto Belo, Bombinhas e Itapema. Esse curso hídrico nasce no Morro da Miséria, a oeste, percorrendo cerca de $10 \mathrm{~km}$ até sua foz no Oceano Atlântico.

O entorno da bacia do Rio Perequê é caracterizado como área pantanosa e como área de captação que se enche de água da chuva por estar em um nível mais baixo que a antepraia (MOURA, 2005). Trata-se de uma área de Preservação Permanente cujo 
objetivo é preservar a vida da fauna de roedores e a vegetação local. É também a forma de controlar a urbanização nas margens do rio, que foi transformada em Reserva Ambiental Municipal Parque das Capivaras.

O Rio Perequê, principal atrativo do Parque e manancial de água, é de suma importância para o município e também faz parte da trilha para educação ambiental. Contando com uma parceria entre a Secretaria de Educação e Esporte, a FAACI realiza trilhas ecológicas com estudantes, ministrando diversas atividades, com reflexões e discussões, de forma lúdica, abordando temas relacionados ao meio ambiente, como: Mata Atlântica, flora, fauna, resíduos sólidos, Rio Perequê e outros.

Assim como em muitas cidades litorâneas, a ocupação dos municípios banhados pelos rios, aconteceu de forma irregular e intensa, com ocupações irregulares das Áreas de Preservação Permanente. No caso das margens do Rio Perequê, alguns trechos foram mais urbanizados incluindo construções de residências, e até mesmo de marinas ilegais. Um dos problemas frequentemente constatados são as ligações clandestinas de esgoto à rede pluvial, bem como o despejo direto de dejetos no rio. Destaca-se que parte da população de Itapema lança seus efluentes domésticos, sem nenhum tipo de tratamento, em valas de drenagem e canalizações ilegais, que desembocam diretamente no Rio Perequê e seus afluentes.

Nesse sentido, faz-se importante a fiscalização das condições das ligações prediais de esgoto na rede coletora municipal, para que as irregularidades não comprometam a qualidade da água do mar e dos rios que drenam a região, além de interferirem negativamente na ETA - Estação de Tratamento do Esgoto. Nessa área de estudo, junto à foz do Rio Perequê e de seu entorno, foi possível constatar a fragilidade da área mais urbanizada, em função de aterros clandestinos e parcelamentos em APPs - Áreas de Preservação Permanente. A margem do Rio Perequê ainda apresenta alguns indicativos remanescentes de vegetação de mangue.

Nas projeções de cenário de elevação do oceano para 2030, nas áreas de topografia plana que distam até 100 metros do leito do rio, estas seriam as mais atingidas 
Mudanças climáticas e planejamento urbano: cenários futuros de aumento do nível do oceano no município de Itapema/SC

Samantha Jandrey, Juarês José Aumond

pela transgressão marinha. No cenário projetado para 2100, a inundação marinha dessas áreas é alarmante, conforme indica a Figura 06.

Figura 06- Projeção do cenário futuro na Área de Recorte Rio Perequê

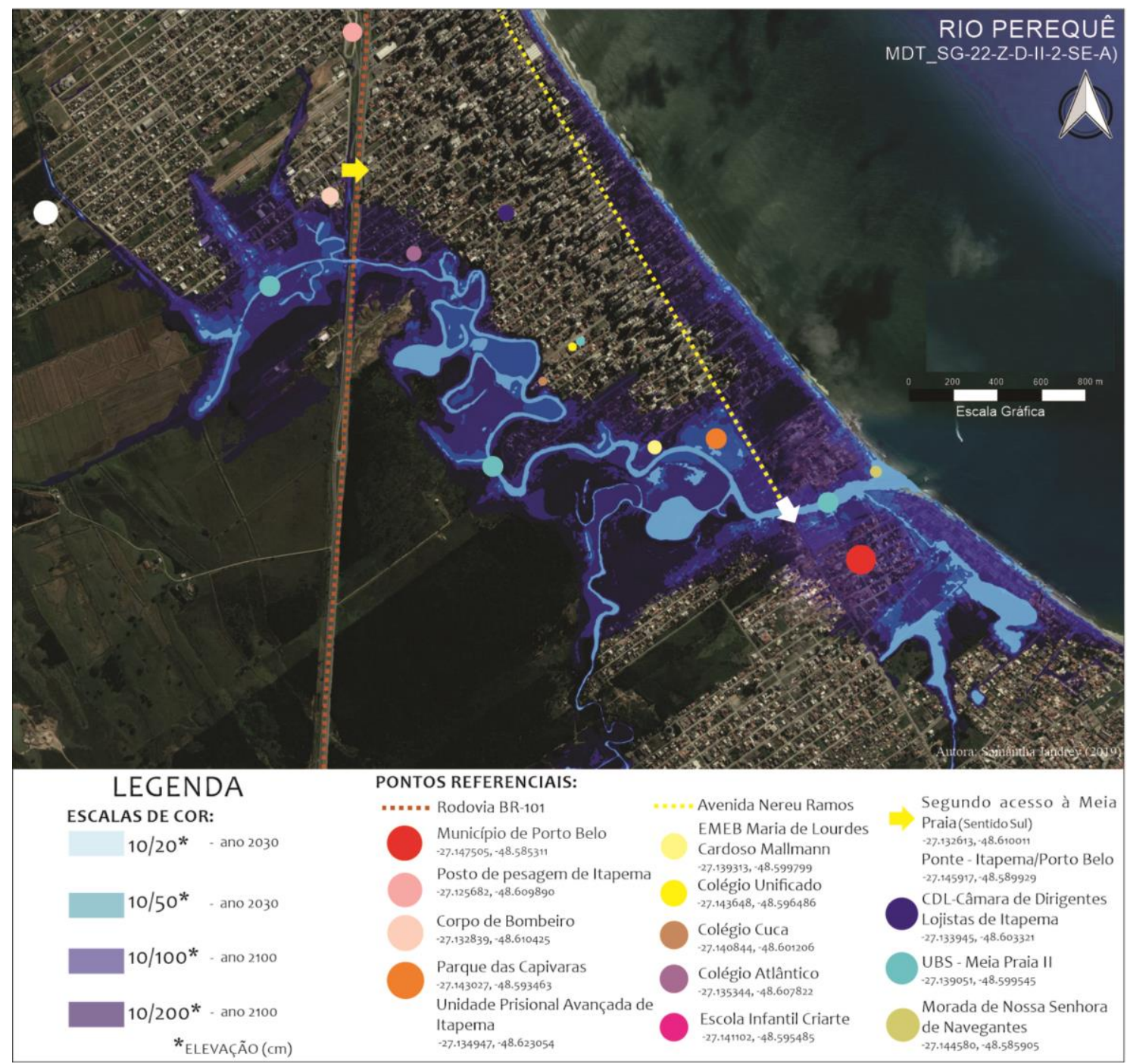

Fonte: Elaborado pela autora, 2019.

Para Moura (2005), o entorno dos rios, pela morfologia e pela umidade, torna-se alagadiço e tende a virar área de mangue que deve ser preservada. Essa unidade paisagística tende a assumir características de áreas salobras, e sofrerá forte impacto com a evolução do aumento de nível do mar. Os rios e mangues têm seu volume de água, 
largura de sua foz (rios) e perímetro (lagoa) aumentados de forma drástica. Interessa informar que a hidrodinâmica desses cenários não foi analisada.

\section{Considerações finais e recomendações}

Os cenários projetados nesta pesquisa sobre a transgressão marinha na área urbana proporcionam uma visão do futuro que permitirá desenvolver estratégias de desenvolvimento urbano, e aumentar a resiliência da cidade de Itapema frente às mudanças climáticas. A relevância dos prognósticos das mudanças climáticas, através das cartografias nesta pesquisa, permitirá aos planejadores e urbanistas atentarem sobre as alterações que irão provocar nas dinâmicas locais, para fins de planejamento e construção de uma cidade mais sustentável e, principalmente, resiliente.

É relevante destacar que as mudanças climáticas são um fenômeno que ocorre em escala global, mas podem se refletir em escalas regionais e locais influenciadas por variáveis e fatores regionais e locais. No caso de Itapema, por ser uma cidade costeira, o impacto do aumento do nível do oceano, e a consequente transgressão marinha, é considerável e preocupante diante dos prognósticos realizados nesta pesquisa. Frente a isso, deve ser assegurada a qualidade do ambiente urbano e natural para o crescimento sustentável, e o planejamento e as ações sobre o espaço precisam ser compatíveis e dialogados para pôr em prática a transição para um sistema integrado com a participação comunitária. Para tanto, a gestão pública precisa se sensibilizar para a relevância da abordagem de ações, planos, estratégias setoriais integradas e sistêmicas de enfrentamento dos efeitos das mudanças climáticas.

Portanto, cabe refletir sobre a importância do planejamento urbano como ferramenta para aparar desigualdades geradas pelo processo de desenvolvimento, tendo este como um meio e não um fim em si mesmo, visto que um dos seus objetivos primordiais é planejar a cidade desejada e, mais do que isso, é construir a cidade desejada garantindo a qualidade de vida à população.

Itapema cresceu de forma desordenada, na velocidade imposta por setores e pelos interesses especulativos das construtoras e imobiliárias; não houve uma política de 
ocupação que levasse em conta a suscetibilidade às inundações, nem as áreas ambientalmente frágeis. As políticas de zoneamento urbano do município de Itapema não se mostraram eficazes para amortecer os impactos da elevação do nível do oceano provocada pelas mudanças climáticas.

Ressalta-se a importância de um estudo específico de elevação do nível do oceano que considere as condicionantes locais - como localização geodésica, efeito de marés e interferência pluviométrica - e inclusão de outras variáveis para fins de planejamento de médio e longo prazos - como tendências de crescimento da população e da área urbana, dinâmicas do mercado imobiliário, fatores econômicos e do meio ambiente, além da inclusão e participação social, entre outros. Os prognósticos, os cenários e as estratégias sugeridos na presente pesquisa serão cruciais também a longo prazo (BRAUN; AUMOND, 2017).

De acordo com Gomes (2018), pode-se concluir que a temática das mudanças climáticas aliada às questões de desenvolvimento constitui uma rica seara para pesquisas acadêmicas. A eustasia já é um problema presente e que demanda ações rápidas de planejamento urbano e ambiental nos municípios litorâneos. Há uma grande necessidade de mobilização nos diversos extratos sociais para que o assunto possa ser difundido, não somente no meio acadêmico, mas para que também chegue ao entendimento do poder público e da comunidade em geral. Transpor os problemas gerados pelas mudanças climáticas e a transgressão marinha significa encontrar maneiras de continuar promovendo o desenvolvimento regional.

\section{Referências}

BRAGA, Roberto. Mudanças climáticas e planejamento urbano: uma análise do Estatuto da Cidade. In: ENCONTRO NACIONAL DA ANPPAS, 6., 2012, Belém. Anais [...]. São Paulo: Anppas, 2012. p. 1-15

BRAUN, Samara. O mar e a cidade: mudanças climáticas e o desenvolvimento urbano em Joinville (SC). 2017. Dissertação (Mestrado em Desenvolvimento Regional) - Programa de Pós-Graduação em Desenvolvimento Regional da Universidade Regional de Blumenau, Blumenau, 2017. 
BRAUN, Samara; AUMOND, Juarês José. ST 4 Simulação de Elevação do Nível do Mar na cidade de Joinville (SC). Anais ENANPUR, Belo Horizonte, v. 17, n. 1, 2017. Disponível em: anpur.com.br. Acesso em: 18 set. 2020.

DAMIANI, Amélia Luisa. Cidades médias e pequenas no processo de globalização: apontamentos bibliográficos. In: LEMOS, Amalia Inés Geraiges de; ARROYO, Mónica; SILVEIRA, Maria Laura. América Latina: cidade, campo e turismo. São Paulo: CLACSO, 2006. Disponível em:

http://bibliotecavirtual.clacso.org.ar/ar/libros/edicion/lemos/08damiani.pdf. Acesso em: 17 abr. 2017.

FARIAS, Vilson Francisco de. Itapema: natureza, história, cultura. Florianópolis, Ed. Do autor, 1999.

FERRARI, Célson. Curso de planejamento municipal integrado: urbanismo. São Paulo: Pioneira, 1984.

GIDDENS, Anthony; VIANNA, Sérgio Besserman. A política da mudança climática. Rio de Janeiro: Zahar, 2010.

GIDDENS, Anthony. Sociologia. 4. ed. Lisboa: Fundação Calouste Gulbenkian, 2004.

GOMES, Anderson de Miranda. A eustasia projetada pelo painel intergovernamental de mudanças climáticas e seus aspectos no desenvolvimento do litoral centro. 2018. Tese (Doutorado em Desenvolvimento Regional) - Programa de Pós-Graduação em Desenvolvimento Regional da Universidade Regional de Blumenau, 2018IBGE - Instituto Brasileiro de Geografia e Estatística. Cidades@2016: Itapema. [Rio de Janeiro]: IBGE, 2017. Disponível em: http://cidades.ibge.gov.br/xtras/perfil.php?codmun=420830. Acesso em: 17 abr. 2017.

IPCC. Painel Intergovernamental para Mudanças Climáticas. A ciência da mudança do clima: sumário técnico do relatório do grupo de trabalho I: quinto relatório de avaliação do IPCC - [Genebra]: IPCC, 2014. Disponível em:

http://www.ipcc.ch/working_groups/working_groups.shtml. Acesso em: 17. mai. 2017.

PINHO, Luciana; REIS, Almir Francisco. Processo de crescimento urbano-turístico: estudo do Balneário Meia Praia, no município de Itapema [Santa Catarina, Brasil]. Labor \& Engenho, Campinas, v.7, n.3, p.142-157, 2013. Disponível em: www.conpadre.org. Acesso em: 28 out. 2017.

LABOURIAU, Maria Lea Salgado. História ecológica da Terra. 2. ed. São Paulo: Blucher, 1998. 
MARICATO, Ermínia. Conhecer para resolver a cidade ilegal. In: CASTRIOTA, Leonardo Barci (org.). Urbanização brasileira: redescobertas. Belo Horizonte: C/Arte, 2003.

MARICATO, Ermínia. Brasil, cidades: alternativas para a crise urbana. 4. ed. Petrópolis: Vozes, 2011.

MINAYO, Maria Cecília de Souza; DESLANDES, Suely Ferreira; CRUZ NETO, Otávio; GOMES, Romeu. Pesquisa social: teoria, método e criatividade. 24. ed. Petrópolis: Vozes, 1994.

\section{MORAES, Antonio Carlos Robert. Contribuição para a gestão costeira do Brasil:}

elementos para uma geografia do litoral brasileiro. São Paulo: Annablume, 2007.

MOURA, Heloísa Figueiredo. Previsões de alterações do nível do mar aplicadas ao planejamento urbano: estudo de caso de Porto Belo, SC/Brasil. 2005. Dissertação (Mestrado em Arquitetura e Urbanismo) - Universidade Federal de Santa Catarina, Florianópolis, 2005.

POLETTE, Marcus; LINS-DE-BARROS, Flavia. Os desafios urbanos na zona costeira brasileira frente às mudanças climáticas. Costas, Cádis, v. 1, p. 165-180, 2012.

REIS, Almir Francisco. Forma Urbana, paisagem e meio ambiente: uma abordagem integrada da transformação urbano-turística do litoral catarinense. Cadernos PROARQ, Rio de Janeiro, v. 1, p. 132, 2009.

SANTOS, Milton. A urbanização brasileira. São Paulo: Hucitec, 1989.

SCHIMIGUEL, Adriana Aparecida. O mercado imobiliário no município de Itapema/SC: o desenvolvimento e suas contradições. 2016. Dissertação (Mestrado em Planejamento Territorial e Desenvolvimento Socioambiental) - Centro de Ciências Humanas e da Educação, Universidade do Estado de Santa Catarina, Florianópolis, 2016.

SIEBERT, Claudia. A evolução urbana de Blumenau: a cidade se forma. In: THEIS, Ivo; MATTEDI, Marcos. (org.). Nosso passado (in)comum. Blumenau: Edifurb, 2000. p. 181-213.

SIEBERT, Claudia. Mudanças climáticas e resiliência urbana. In: ENCONTRO NACIONAL DA ANPUR, 15. 2015, Belo Horizonte. Anais [...]. Recife: UFPE, 2013.

SDS - Secretaria de Desenvolvimento Sustentável. Sistema de Informações Geográficas de Santa Catarina (SIGSC). Florianópolis, 2012. Disponível em: www.sigsc.sds.sc.gov.br. Acesso em: 10 abr. 2019. 
SILVA, Maria Emília Martins da. Gestão sustentável da orla marítima em destinos turísticos costeiros: a percepção dos atores sociais. 2013. Dissertação (Mestrado em Engenharia e Gestão do Conhecimento) - Programa de Pós-Graduação em Engenharia e Gestão do Conhecimento, Universidade Federal de Santa Catarina, Florianópolis, 2013.

SOUZA, Marcelo José Lopes; RODRIGUES, Glauco Bruce. Planejamento urbano e ativismos sociais. São Paulo: Unesp, 2004.

SPOSITO, Maria Encarnação Beltrão. Capitalismo e urbanização. São Paulo: Contexto, 2005.

STROHAECKER, Tânia Marques. Dinâmica populacional. In: MACRODIAGNÓSTICO DA ZONA COSTEIRA E MARINHA DO BRASIL. Brasília: Ministério do Meio Ambiente, Secretaria de Mudanças Climáticas e Qualidade Ambiental, 2008. p. 59-92

UNITED NATIONS HUMAN SETTLEMENTS PROGRAMME. Cities and climate change: global report on human settlements. London: UN-Habitat, 2011

ZEMKE, Miriam Margareth. Processo recente de adensamento imobiliário e verticalização em Itapema/SC. 2007. Dissertação (Mestrado em Geografia) - Programa de Pós-Graduação em Geografia, Universidade Federal de Santa Catarina, Florianópolis, 2007. 